Parcours de recherche en SIC: littérature scientifique, méthodes et terrain

\title{
Julie Bouchard : Comment le retard vient aux Français. Analyse d'un discours sur la recherche, l'innovation et la compétitivité 1940-1970
}

Paris : Septentrion, 2008, 328 pages

Lucile Desmoulins

\section{(2) OpenEdition}

Journals

Édition électronique

URL : http://journals.openedition.org/edc/959

DOI : $10.4000 /$ edc. 959

ISSN : 2101-0366

Éditeur

Université de Lille

Édition imprimée

Date de publication : 1 avril 2009

Pagination : 153-156

ISBN : 978-2-917562-01-7

ISSN : $1270-6841$

\section{Référence électronique}

Lucile Desmoulins, « Julie Bouchard: Comment le retard vient aux Français. Analyse d'un discours sur la recherche, l'innovation et la compétitivité 1940-1970», Études de communication [En ligne], 32 | 2009, mis en ligne le 31 août 2009, consulté le 22 septembre 2020. URL : http:// journals.openedition.org/edc/959; DOI : https://doi.org/10.4000/edc.959

Ce document a été généré automatiquement le 22 septembre 2020.

(c) Tous droits réservés 


\section{Julie Bouchard : Comment le retard vient aux Français. Analyse d'un discours sur la recherche, l'innovation et la compétitivité 1940-1970}

Paris : Septentrion, 2008, 328 pages

Lucile Desmoulins

\section{RÉFÉRENCE}

Julie Bouchard : Comment le retard vient aux Français. Analyse d'un discours sur la recherche, l'innovation et la compétitivité 1940-1970. Paris : Septentrion, 2008, 328 pages.

L'ouvrage de Julie Bouchard met en lumière le lien entre deux discours dominants dans les années d'après Deuxième guerre mondiale, celui d'un retard français en matière de sciences et de techniques et celui relatif au projet de modernisation de la société française figurant dans les rapports des Commissions du Plan et de la Délégation générale à la recherche scientifique et technique (DGRST). L'analyse confronte les enjeux économiques, politiques, sociaux et communicationnels liés aux sciences que le politique finance et aux techniques qui en découlent en vue de leur appropriation par la société. La " petite musique » du retard, sa « douce mélancolie ", rythme les discours des journalistes, des politiques et des chercheurs eux-mêmes. Cette thématique récurrente est analysée par Julie Bouchard à partir des années glorieuses de la mise en place de la politique de recherche contemporaine au moment de la création de la DGRST. 
Récusant la posture évaluative, le propos n'est pas de mesurer le retard, de comparer des situations nationales ou de déceler les causes d'un retard postulé. C'est le discours sur le retard dans sa dimension historique et médiatique, de sa mise sur agenda à son instrumentalisation, qui est explicité à l'épreuve des faits tels qu'ils ont été vécus et décrits par les acteurs de la recherche et de la planification. S'attachant au discours politique décliniste, Julie Bouchard analyse les conditions sociales, institutionnelles, intellectuelles et matérielles qui ont présidé à la production et à la circulation de la rhétorique du retard. Elle tord par ce biais le cou à certains mythes tenaces. La profusion du discours sur le retard n'est, par exemple, pas le signe d'une incapacité à se transformer, mais bien plutôt celui de la quête obsessionnelle d'une amélioration. Du point de vue de l'histoire économique, le retard ne s'oppose pas à l'idéologie du progrès qui s'est propagé à partir du XVII siècle, il en est le revers à travers la récurrence des débats entre «tardophiles» et "tardophobes». Le "tardophile» postule la convergence socio-économique des nations, il relativise le retard mais s'exprime paradoxalement avec un certain pessimiste sur le monde qu'il observe. Le "tardophobe" identifie et naturalise les divergences de modèles de développement socio-économique, des écarts qu'il observe pourtant sereinement.

L'étude de la genèse lexicographique du mot « retard » résorbe partiellement les tensions entre « tardophilie » et " tardophobie » en situant le discours sur le retard dans sa dimension de construction sociale et de référentiel agissant. Le discours sur le retard est une stigmatisation de la réalité qui a acquis la force d'une rhétorique de l'insuffisance et d'une injonction au changement. Ainsi, la science et la technologie ont progressé en France « non simplement malgré mais bien avec la rhétorique du retard ». L'analyse se concentre sur l'histoire institutionnelle de la planification en tant qu'espace discursif à l'intérieur duquel le retard a eu un rôle moteur.

La réflexion théorique prend sa source dans un corpus homogène de textes : les rapports sur la recherche réalisés par le Commissariat général du Plan dans le cadre des plans quadriennaux qui se sont succédés après la Seconde guerre mondiale et jusqu'en 1993. Ce corpus n'épuise pas les usages politiques et sociaux de la rhétorique du retard, mais il livre un aperçu de l'évolution de ces usages, entre continuité et transformations. Il permet d'élucider les mécanismes de «l'engendrement mutuel » qui ont présidé la relation entre retard et planification. Prégnant au début des années 1950 dans les réflexions planificatrices sur la recherche et notamment en ce qui concerne les sciences sociales et les disciplines contribuant au progrès médical, il va ensuite contaminer d'autres disciplines : électronique, informatique, chimie, agronomie, etc. Le discours sur le retard fait l'objet d'un véritable engouement notamment à la fin des années 1950 et 1960 .

Quatre grands "régimes de normativité » ont co-existé selon des équilibres variables pendant toute la période étudiée. Le premier concerne une quête du progrès et une glorification de la science en elle-même, associées à une conception scientiste traditionnelle selon laquelle le progrès social découle naturellement des progrès scientifiques. Le deuxième met en évidence les interdépendances disciplinaires qui sont le fondement du progrès scientifique et, plus rarement, les interdépendances fécondes entre la société des scientifiques et la société dans son ensemble. Dans un troisième régime, le discours sur le retard est appréhendé en tant qu'avatar de comparaisons/ compétitions géographiques. Dans cette optique, les recherches nationales sont 
inscrites dans une exigeante et coûteuse course de fond et les États-unis font figure à la fois de modèle et de menace. Enfin, le dernier régime de normativité met en exergue des retards évalués et dénoncés en fonction d'objectifs fixés dans un cadre administratif en fonction de principes managériaux. Ces deux derniers régimes doivent leur succès au développement de l'outil statistique favorisé par l'Organisation de coopération et de développement économiques (OCDE).

Læ rhétorique du retard, du déclin, de la détérioration, est inséparable de celle $\mathrm{du}$ redressement, d'une modernisation nécessaire de l'outil de recherche et de la société par cet outil. Croisant l'analyse de la rhétorique du retard avec celles d'une époque et d'une structure, le livre de Julie Bouchard a le mérite de tourner la page de la nostalgie d'un âge d'or de la recherche française caractérisé par le tandem volonté politique/mobilisation collective. Au terme d'un panorama lexicographique, historique et communicationnel, l'auteure propose une réflexion s'appuyant sur le manichéisme du retard (vrai/faux, pour/contre, bon/mauvais) pour mieux le dépasser. Les discours, représentations et croyances sur la science sont nombreux, souvent contradictoires et, selon elle, certains recèlent « de pures inepties ». Qu'en est-il à l'heure actuelle ? Selon de nombreux analystes, essayistes et politiques, la recherche scientifique française serait sur le déclin d'où une baisse de la compétitivité de l'industrie nationale. Pendant la soirée du 5 février, devant les 15,1 millions de téléspectateurs que réunissaient trois chaînes (France 2, TF1 et M6), le président Nicolas Sarkozy intervenait sous la forme d'une interview de journalistes: "Je suis inquiet de voir depuis des années les universités françaises reculer dans les classements internationaux [...]. [Sur le statut des enseignants-chercheurs, il ajoutait ceci...] Tout le monde me dit [qu'] il y a un malaise dans la recherche, c'est le fameux décret de 1984, il faut changer ça ». Ces phrases renvoient explicitement au retard et à son corollaire, l'injonction au changement. Elles offrent l'apparence séductrice d'un adossement du discours au triptyque classique: discours sur le retard, comparaison géographique, statistique et pourtant...

Parfois le discours décliniste eut des vertus mobilisatrices, il incita les politiques à investir dans la recherche et les universités. Peut-on cependant analyser sans inquiétude un discours décliniste qui ne s'accompagnerait ni d'une analyse des données objectives susceptibles de fonder ce discours, ni d'une mobilisation en faveur de la recherche? Qu'en est-il du sens d'un discours si ouvertement instrumentalisé et qui s'accompagne d'une rupture du dialogue entre scientifiques et politiques? L'actualité de la controverse sur le retard scientifique et technologique rend la lecture de "Comment le retard vient aux Français? "particulièrement éclairante, notamment grâce à l'érudition méticuleuse de l'analyse contextuelle historique et communicationnelle du discours décliniste. 